\title{
Hemangioma of tongue
}

\author{
Manmohan Agarwal ${ }^{1}$, Lakshmi Agarwal ${ }^{2}$, Vikrant Mathur $^{3}$ \\ ${ }^{1}$ Department of Oncosurgery, Pushpadi Cancer Care Center, Kota, India; ${ }^{2}$ Department of Pathology, Government Medical College, Kota, India; \\ ${ }^{3}$ Department of Head and Neck Surgery, Annandam ENT Hospital, Kota, India \\ Correspondence to: Dr. Manmohan Agarwal. Department of Oncosurgery, Pushpadi Cancer Care Center, Kota, India. Email: mag.cancer@gmail.com.
}

Received: 11 March 2018; Accepted: 15 March 2018; Published: 13 April 2018.

doi: 10.21037/acr.2018.03.04

View this article at: http://dx.doi.org/10.21037/acr.2018.03.04

Hemangioma is a benign proliferation of blood vessels. Oral hemangioma is a common entity and represents $14 \%$ of all hemangiomas (1). It was first reported in 1841 as bluish excrescence and erectile tissue (2). It is usually presents at birth but can occur rarely in adults due to frequent trauma to the blood vessels of mucosa. The lip mucosa ( $63 \%$ of cases) is the most frequent site followed by the buccal mucosa (14\% of cases), and the lateral borders of the tongue (14\% of cases), but it may occur at any oral or pharyngeal location.

International Society for the Study of Vascular Anomalies (ISSVA) has recently provided guidelines to differentiate these two conditions, according to the novel classification first published by Mulliken et al., in $1982(3,4)$. They are broadly classified into two groups: hemangioma and vascular malformation.

A 50-year-old female presented with a swelling in the ventral surface of anterior one third tongue. She noticed it 6 months back which was gradually increasing. She is neither a tobacco chewer nor using any denture. It was not associated with features of pain, fever, difficulty in the speech and swallowing. The past medical, dental and family histories were not significant and the vitals were within normal limit.

Intra-oral examination revealed a solitary elliptical swelling measuring about $1.5 \mathrm{~cm} \times 2 \mathrm{~cm}$ in size. The surface appeared to be smooth and granular with well-defined borders. The swelling was blackish in colour. Adjacent area was normal (Figure 1). On palpation the swelling was soft in consistency, non-mobile, non-tender, afebrile with no palpable thrills and did not blanch on compression.

Patient was taken for surgery under general anaesthesia. The feeding vessel was identified and ligated. The mass was enucleated along with capsule and the defect was closed primarily (Figure 2).

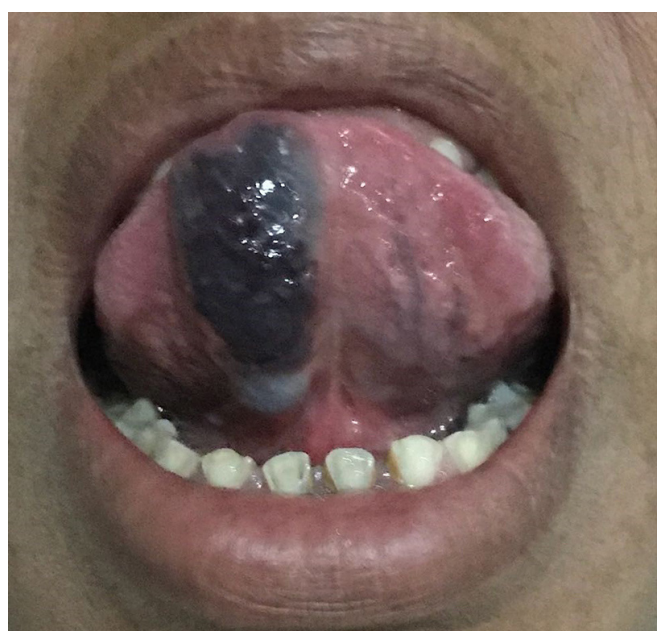

Figure 1 Photograph showing blackish lesion on the ventral surface of tongue.

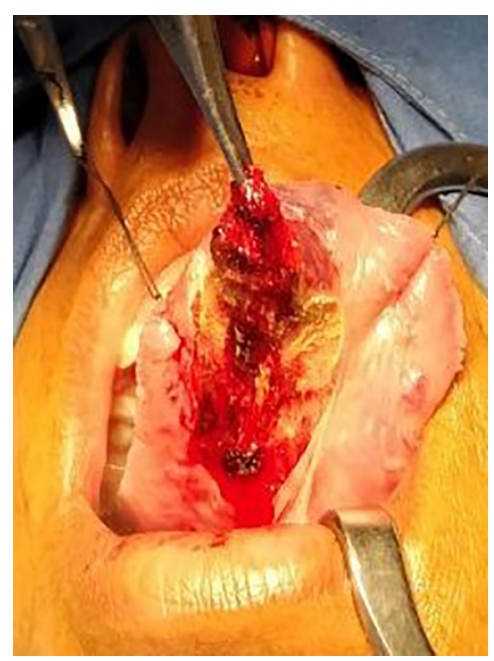

Figure 2 Intraoperative image after the removal of lesion. 
On histopathological examination, the mass revealed the features of cavernous hemangioma comprising multiple dilated vascular channels.

Though it is a benign tumor sometimes it can be confused with vascular malignancy or melanoma due to painless mass and increasing in size. Proper clinical evaluation and management can benefit the patient.

\section{Acknowledgements}

The authors would like to thank Shankar Agarwal (Director of Pushpadi Cancer Care Centre) and Manisha Khangwal (Laboratory Technician of Pushpadi Cancer Care Centre).

\section{Footnote}

Conflicts of Interest: The authors have no conflicts of interest to declare.

Informed Consent: Written informed consent was obtained from the patient for publication of this manuscript and any accompanying images.

\section{References}

1. Okoje VN, Alonge TO, Olusanya AA. Intra-tumoral ligation and the injection of sclerosant in the treatment of lingual cavernous hemangioma. Niger J Med 2011;20:172-5.

2. Harris CA. A physiological and pathological inquiry concerning the physical characteristics of the human teeth and gums, the salivary calculus, the lips and the tongue, and the fluids of the mouth. Am J Dent Sc 1841;2:39-120.

3. Kamala KA, Ashok L, Sujatha GP. Cavernous hemangioma of the tongue: A rare case report. Contemp Clin Dent 2014;5:95-8.

4. Mulliken JB, Glowacki J. Hemangiomas and vascular malformations in infants and children: A classification based on endothelial characteristics. Plast Reconstr Surg 1982;69:412-22. doi: 10.21037/acr.2018.03.04

Cite this article as: Agarwal M, Agarwal L, Mathur V. Hemangioma of tongue. AME Case Rep 2018;2:11. 